Research Article

\title{
Optimization of Temperature-Control Measures for Concrete Structures: A Case Study of the Sluice Project
}

\author{
Yaoying Huang (iD \\ College of Hydraulic \& Environmental Engineering, China Three Gorges University, Yichang, Hubei 443002, China \\ Correspondence should be addressed to Yaoying Huang; huangyaoying@sohu.com
}

Received 26 April 2018; Accepted 26 June 2018; Published 15 July 2018

Academic Editor: Hugo Rodrigues

Copyright (C) 2018 Yaoying Huang. This is an open access article distributed under the Creative Commons Attribution License, which permits unrestricted use, distribution, and reproduction in any medium, provided the original work is properly cited.

\begin{abstract}
Temperature control and crack prevention in sluice pier concrete is a key issue in the early design and construction period. Strong surface insulation may lead to cracks after formwork removal, while weak surface insulation may result in a high crack risk in the early age. The water-cooling measure may also cause severe cracks at a rapid cooling rate. Therefore, the optimum temperature control scheme should be comparatively studied against the alternatives. In this paper, we investigate crack prevention in sluice pier concrete as a multiple-factor system optimization problem and investigate an optimization method for temperature-control measures using the uniform design method and a neural network model. The minimum ratios for the internal and surface points of the sluice pier concrete are taken as inputs, and the corresponding combinations of temperature-control parameters based on the uniform design method are taken as outputs. Combined with a sluice project, the optimization method for the temperaturecontrol measures is implemented. The analysis results show that internal pipe cooling combined with reasonable surface heat preservation measures should be employed, and a low concrete pouring temperature is more beneficial than a low cooling temperature and long duration for crack prevention in sluice pier concrete.
\end{abstract}

\section{Introduction}

Observations from many sluice projects have established that cracks often manifest during construction. Therefore, temperature control and crack prevention in sluice pier concrete remain one of the main technical issues in the early design and construction period. Engineering practices indicate that surface heat preservation can reduce the temperature difference between the surface and internal concrete of a pier as well as the surface tensile stress at the early age but can elevate the temperature increase and the amplitude of the temperature drop, resulting in markedly increased internal tensile stress in the later stage. In addition, to better recycle the formwork, the insulation material pasted on the outside of the formwork is usually removed when the concrete is cured for several days. Therefore, sluice pier concrete poured during low-temperature seasons can suffer a prominent cold hammer imposed by the ambient temperature after formwork removal when the initial insulation effect is excessive [1]. Therefore, adoption of internal pipe cooling combined with surface heat preservation should be employed to avoid cracks. However, the water-cooling measure that can reduce the internal temperature and the difference between the internal and the external temperature can still cause severe cracks when the cooling rate is too high [2].

To better reflect the growth rate of the adiabatic temperature rise, elasticity modulus, and strength of concrete, Zhu and Yang [3] proposed the concept of the semimature age of concrete, that is, the age in which the adiabatic temperature rise or the strength of concrete reaches half of the final value. Under this definition, the smaller the semimature age of concrete is, the faster the concrete matures. Since a sluice pier is often poured by pumping concrete with a high slump whose heat release and heat release rate are generally higher than those of conventional concrete, the semimature age of pumping concrete is generally small. As a result, the internal temperature will rise rapidly, leaving no time for natural or artificial cooling, even when certain measures (such as increasing the water flow in the cooling 
pipe, adopting small cooling pipe spacing, and reducing the cooling water temperature) are implemented. Consequently, the concrete will undergo a large subsequent temperature drop that produces high thermal stress. Therefore, the optimum temperature control scheme should be investigated based on comparative technical and economical studies of the alternatives.

In fact, temperature control and crack prevention in sluice pier concrete depend on temperature-control measures, the thermal and mechanical parameters of the concrete, the structural type, and the construction schedule. Therefore, a complex multiple-factor system optimization problem exists. Some studies have focused on comparative analysis of several temperature schemes for temperature control and crack prevention [4-6], but little attention has been directed toward multiple-factor optimization. Since optimization methods are widely employed in concrete material and concrete engineering [7-9], temperature control and crack prevention in sluice pier concrete are regarded as a complex multiple-factor system optimization problem. Here, the uniform design method and a neural network are adopted to optimize the multiple temperaturecontrol factors.

\section{Optimization Principle for Temperature- Control Measures}

2.1. Simulation Analysis Principle for the Temperature Field and Viscoelastic Thermal Stress Field of Concrete Structures. Water pipe cooling is the main temperature-control measure in concrete construction. The simulation of the pipe cooling effect is a challenging problem in temperature field simulation of the concrete structures [10-16]. In general, two main calculation methods exist for analyzing the pipe cooling effect [10-12]: the finite element method (FEM) of pipe cooling and the equivalent heat conduction method (EHCM) of pipe cooling. In the first method, to reflect the large temperature gradient near cooling pipes, finite elements near the cooling pipes are densely meshed, and the iterative method is used to calculate the change of temperature along the cooling pipes caused by heat exchange between the concrete and the cooling water. The water temperature increment per unit length of water pipe is $[10]$

$$
\Delta T_{\mathrm{w}}=\frac{-\lambda}{c_{\mathrm{w}} \rho_{\mathrm{w}} q_{\mathrm{w}}} \iint_{\Gamma^{0}}\left(\frac{\partial T}{\partial n} d s\right),
$$

where $\lambda$ is the thermal conductivity of concrete, $c_{\mathrm{w}}$ and $\rho_{\mathrm{w}}$ are the water specific heat capacity and the bulk density, respectively, $q_{\mathrm{w}}$ is the water pipe flow, $\partial T / \partial n$ is the temperature gradient of the water pipe wall, $n$ is the water pipe wall interior normal direction, and $\Gamma^{0}$ is the pipe boundary.

In the other method, cooling pipes are taken as a negative heat source to consider the effect of pipe cooling in an average manner, and the temperature field can be obtained using a general FEM mesh instead of dense finite elements. At this point, the equivalent heat transfer equation for the water pipe cooling is $[11,12]$

$$
\frac{\partial T}{\partial t}=a\left(\frac{\partial^{2} T}{\partial x^{2}}+\frac{\partial^{2} T}{\partial y^{2}}+\frac{\partial^{2} T}{\partial z^{2}}\right)+\left(T_{0}-T_{w}\right) \frac{\partial \phi}{\partial t}+\theta_{0} \frac{\partial \Psi}{\partial t}
$$

where $T$ is the concrete temperature, $t$ is time, $a$ is the thermal conductivity of concrete, $T_{0}$ is the concrete initial temperature, $T_{\mathrm{w}}$ is the water inlet temperature, $\theta_{0}$ is the final adiabatic temperature rise, $\phi$ and $\Psi$ are functions of the water pipe cooling effect, and $x, y$, and $z$ are coordinates.

The EHCM of pipe cooling is usually employed to simulate mass concrete-embedded water pipe cooling to reduce the large numbers of finite element meshes. While the sluice pier is a thin-walled concrete structure, the FEM of pipe cooling is more appropriate to obtain the temperature field. Therefore, in this paper, the FEM of pipe cooling is employed to simulate the temperature field of sluice pier concrete.

Once the temperature field of the sluice pier is obtained, the viscoelastic thermal stress field is analyzed. The finite element control equation for calculating the viscoelastic thermal stress field is

$$
\mathbf{K} \Delta u_{n}=\Delta P_{n}^{L}+\Delta P_{n}^{c}+\Delta P_{n}^{T}+\Delta P_{n}^{a},
$$

where $\mathbf{K}$ is the global stiffness matrix of the $n$th time step, $\Delta u_{n}$ is the node displacement increment of the $n$th time step, and $\Delta P_{n}^{L}, \Delta P_{n}^{c}, \Delta P_{n}^{T}$, and $\Delta P_{n}^{a}$ are the increment of the nodal load caused by external load, creep, temperature, and autogenous volume deformation, respectively, which can be found in a study by Zhu [12].

\subsection{Optimization Method for Temperature-Control Measures}

2.2.1. The Principle of Uniform Design. The mathematical principle of uniform design is the consistent distribution theory in number theory [17-19]. This approach combines number theory with multivariate statistics; the combined approach can be classified as a pseudo-Monte Carlo method. The test points are considered as evenly distributed in the test range in uniform design, and the principle of uniform design for selecting the test representative is "evenly distributed" rather than "neatly comparable," thereby ensuring that the test point exhibits a uniform distribution of the statistical properties. Therefore, each level of each factor conducts only one test, and the test points of any two factors are at the grid lattice point with only one test point at each row of per column. Uniform design focuses on the fact that the test points are considered to be spread evenly within the scope of the test to obtain the most information through minimal testing, thereby reducing the number of tests relative to orthogonal design. Therefore, the uniform design method is particularly suitable for multiple-factor and multiple-level tests and situations in which the system model is completely unknown. The uniform design method is used in engineering practice. Here, we employ the uniform design method to design the combinations of multiple temperaturecontrol factors and multiple-level parameters to obtain the most information regarding the feasible domain space for the temperature-control parameters with the smallest number of parameters. 


\subsubsection{Optimization of the Temperature-Control Measures for} Pier Concrete Based on the Uniform Design Method and a Neural Network Model. According to the aforementioned analysis, temperature control and crack prevention of sluice pier concrete are regarded as a complex multiple-factor system optimization problem, and intelligent algorithms are adopted to solve this problem.

Since materials and structures have usually been optimized by designers before concrete pouring, we optimize the temperature-controlled parameters for sluice concrete using the known thermal and mechanical material parameters of concrete. Because the optimization of a multiple-factor system can easily fall into a local optimum, the uniform design method and a neural network model $[20,21]$ are employed. Considering that the driving force of concrete cracking is the principal tensile stress rather than the maximum temperature or rate of temperature decrease, we focus on the ratio of the relationship between the principal tensile stress and the tensile strength at the corresponding age of the sluice pier concrete; this ratio can be expressed as follows:

$$
R=\frac{\left[\sigma_{1}\right]_{\tau}-\sigma_{1 \tau}}{\left[\sigma_{1}\right]_{\tau}},
$$

where $\sigma_{1 \tau}$ refers to the principal tensile stress of the concrete at the moment of $\tau$ and $\left[\sigma_{1}\right]_{\tau}$ refers to the tensile strength of the concrete at the moment of $\tau$.

Thus, the mathematical optimization model for optimization of multiple temperature-control factors can be described as follows:

Determine

$$
\mathbf{X}=\left[x_{1} x_{2} \cdots x_{n}\right]
$$

to make

$$
R=f(\mathbf{X}) \longrightarrow R^{\mathrm{opt}},
$$

and meet the constraints: $\underline{x}_{1} \leq x_{1} \leq \bar{x}_{1}, \underline{x}_{2} \leq x_{2} \leq \bar{x}_{2}, \ldots$, $\underline{x}_{n} \leq x_{n} \leq \bar{x}_{n}$. where $\underline{x}_{m}$ and $\bar{x}_{m}$ are the upper and lower limits of the temperature-control factor $(m=1,2, \ldots, n)$, respectively.

In the following, optimization of the multiple temperature-control factors in (6) using the uniform design method and a neural network model is presented. The main steps are as follows.

First, generate training samples of the neural network using finite element numerical methods.

(a) The possible range of pouring temperature, the surface insulation effect, the pipe cooling temperature, flow and duration are first estimated, among other parameters. According to the possible range of the parameters to be optimized $\mathbf{X}=\left\{x_{1}, x_{2}, \ldots, x_{n}\right\}$, the combinations of the parameters are constructed by applying the uniform design method.

(b) Establish the finite element model for the sluice pier with pipe cooling. Next, the temperature and viscoelastic thermal stress fields are analyzed using the aforementioned combinations of temperature-control parameters. Therefore, the maximum principal tensile stresses inside the concrete pier and on its surface can be obtained, and the ratio $R$ between the principal tensile stress and the tensile strength at the corresponding age is calculated.

(c) The minimum values $\left(R_{\text {in }}\right)_{\min }$ and $\left(R_{\text {sur }}\right)_{\min }$ inside the concrete pier and on its surface are taken as the inputs of the neural network, and the combinations of parameters $\mathbf{X}=\left\{x_{1}, x_{2}, \ldots, x_{n}\right\}$ are taken as the outputs to form the training samples.

Second, train the neural network with the above samples to obtain a reasonable neural network model.

Finally, according to the design requirements and engineering analogy, the optimal values of the ratios between the maximum principal tensile stresses and the tensile strength are determined. Next, the optimal values $R_{\mathrm{in}}^{\mathrm{opt}}$ and $R_{\text {sur }}^{\text {opt }}$ are input into the trained neural network, and the outputs are the optimized pouring temperature, surface insulation parameter, pipe cooling temperature, water flow, and duration of cooling.

The neural network model based on the uniform design method is shown in Figure 1.

\section{Case Study of a Sluice Project}

A grade-III medium-sized sluice project at Huaihe River in China is taken as a study case, as shown in Figure 2. The sluice has a designed flood flow of $600 \mathrm{~m}^{3} \cdot \mathrm{s}^{-1}$ and consists of 5 holes, each with a width of $8 \mathrm{~m}$. The height of the pier is $8.5 \mathrm{~m}$, and the length of the sluice chamber along the water flow is $15.5 \mathrm{~m}$. The elevation of the bottom slab is $21.0 \mathrm{~m}$. The thickness of the middle pier is $1.2 \mathrm{~m}$. The thickness of the bottom slab is $1.4 \mathrm{~m}$. The thickness of the edge pier is $0.9 \mathrm{~m}$. In this project, pump concrete, strength grade C25, and aggregate grade 2 are employed. The construction of the sluice project began during the dry winter season. The period of pouring concrete is from February to April.

\subsection{Determination of the Temperature-Control Parameters to} Be Optimized. Considering that the thermal and mechanical material parameters of concrete have been obtained from laboratory tests and the engineering analogy before concrete pouring, in this study, we conducted optimization of temperature-control measures with the known thermal and mechanical parameters of concrete.

According to the construction schedule of the sluice project and to better recycle the formwork, newly poured concrete must be protected by formwork pasted by the insulation material on the outside for 7 days, and then, the formwork is removed. At 1-day internal, the concrete pier surface is covered by heat insulating materials. In addition, steel pipes for cooling are placed in the middle of the pier with $1 \mathrm{~m}$ vertical spacing, and the radius of the pipe is $0.0125 \mathrm{~m}$.

Because the semimature age of pump concrete is small (only 1.5 days), the effect of increasing the water flow of the water pipe to control the maximum temperature of the pier concrete is not obvious. Moreover, the water-cooling measure can still cause severe cracks when the cooling 


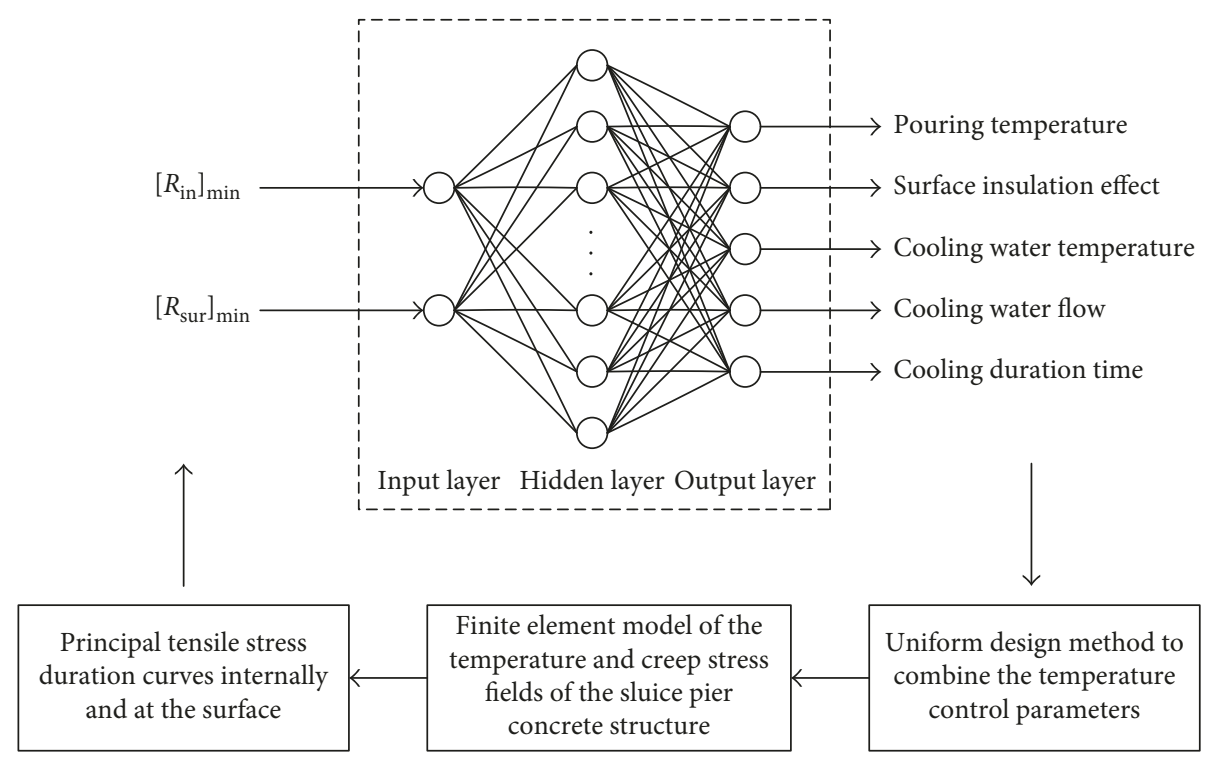

FIGURE 1: Neural network optimization model based on the uniform design method.

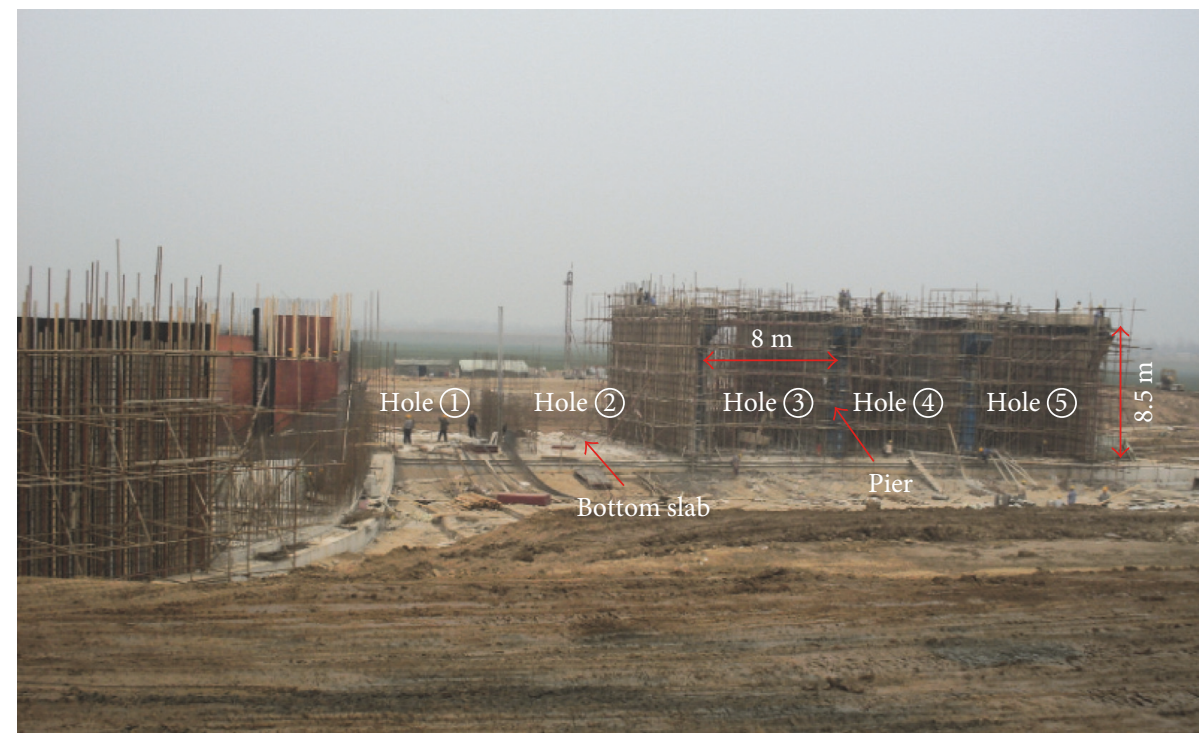

Figure 2: A sluice project in the construction period at Huaihe River in China.

rate is too high. Therefore, the water flow is not selected for optimization, and the water flow in the pipes is $24 \mathrm{~m}^{3}$ per day based on engineering practices. Considering the high risk of cracking at the early age of the sluice pier concrete, four parameters are selected for optimization: the heat insulating material parameter within 7 days, the pouring temperature, the water temperature in the cooling pipes, and the duration of cooling.

\subsection{Finite Element Model of the Sluice Pier Concrete. To} simulate the pipe cooling effect with the FEM of pipe cooling, dense finite elements around the cooling pipes are constructed, as shown in Figure 3.

A middle pier, cooling pipes, and the sluice slab and its foundation are meshed using three-dimensional hexahedron

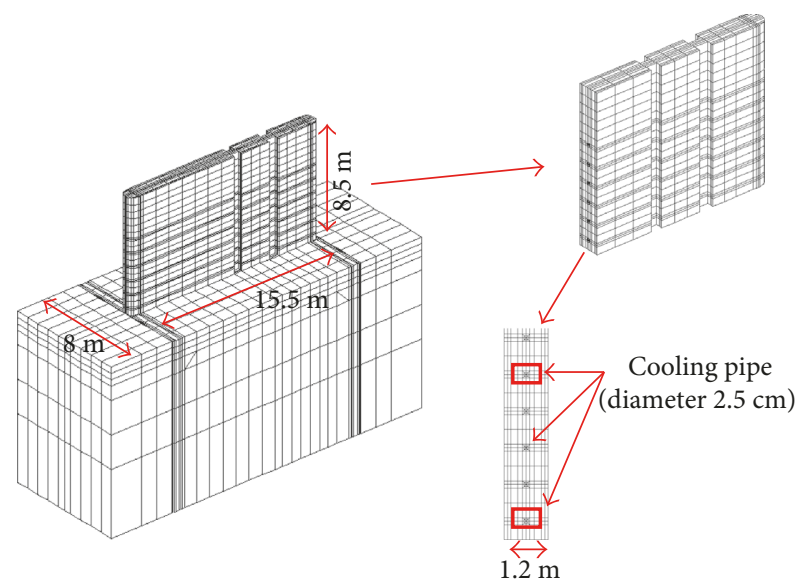

FIGURE 3: Finite element model with pipe cooling of the sluice pier. 
TABLE 1: Thermal parameters for the sluice pier concrete.

\begin{tabular}{lcccc}
\hline Concrete type & Thermal conductivity $\left(\mathrm{kJ} /\left(\mathrm{m} \cdot \mathrm{h} \cdot{ }^{\circ} \mathrm{C}\right)\right)$ & Thermal diffusivity $\left(\mathrm{m}^{2} / \mathrm{h}\right)$ & Specific heat $\left(\mathrm{J} / \mathrm{kg} \cdot{ }^{\circ} \mathrm{C}\right)$ & Density $\left(\mathrm{kg} / \mathrm{m}^{3}\right)$ \\
\hline Pump concrete & 10.838 & 0.004783 & 952 & 2379 \\
\hline
\end{tabular}

TABLE 2: Temperature-control parameters for the 4 factors and 4 levels.

\begin{tabular}{lcccc}
\hline Levels & $\begin{array}{c}\text { Factor A } \\
\text { Cooling water } \\
\text { temperature }\left({ }^{\circ} \mathrm{C}\right)\end{array}$ & $\begin{array}{c}\text { Factor B } \\
\text { Cooling } \\
\text { duration }(\text { days })\end{array}$ & $\begin{array}{c}\text { Factor C } \\
\text { Surface exothermic } \\
\text { coefficient }\left(\mathrm{kJ} /\left(\mathrm{m}^{2} \cdot \mathrm{h}^{\circ}{ }^{\circ} \mathrm{C}\right)\right)\end{array}$ & $\begin{array}{c}\text { Factor D } \\
\text { Pouring }\end{array}$ \\
\hline 1 & 12 & 3 & 5 & 15 \\
2 & 14 & 4 & 23.5 & 18 \\
3 & 16 & 5 & 42 & 21 \\
4 & 18 & 6 & 60.5 & 24 \\
\hline
\end{tabular}

8-node isoparametric elements. A total of 11,860 elements and 14,321 nodes exist in the finite element model. When simulating the temperature field, the 4 sides and bottom face of the foundation are taken as the thermal insulation boundaries, and the surfaces of the bottom slab and the pier are taken as a third kind boundary condition. When simulating the stress field, the bottom boundary of the foundation adopts displacements constrained to zero, and the 4 sides of the foundation adopt connecting rod support. Other boundaries are all free deformation surfaces.

\subsection{Calculation Loads and Thermal and Mechanical} Parameters. For simulation analysis of the temperature field, according to the results of concrete experiments in the laboratory, the adiabatic temperature rise of concrete adopts a hyperbolic expression of $\theta(\tau)=\theta_{0} \tau /(n+\tau)$. $\theta_{0}$ is the final adiabatic value, and $\theta_{0}=51.6^{\circ} \mathrm{C} ; n$ refers to the adiabatic temperature rise rate, and $n=1.5$ days; and $\tau$ is the concrete age. The other thermal parameters, such as the thermal conductivity of concrete, thermal diffusivity, specific heat, and bulk density, are shown in Table 1. The local monthly average temperature $T_{\mathrm{a}}$ is taken as the ambient temperature, $T_{\mathrm{a}}=15.375+12.949 \cos [(\pi / 6)(t-6.619)]$, and $t$ is time.

For simulation analysis of the stress field, the self-weight, thermal load, and creep are considered. The concrete elasticity modulus is expressed as $E(\tau)=40400 \tau /(3.5+\tau) \mathrm{MPa}$, and $\tau$ is the concrete age. The thermal expansion coefficient is $\alpha=1 \times 10^{-5} /{ }^{\circ} \mathrm{C}$. The tensile strength is expressed as $\sigma_{0}(\tau)=3.8 \tau /(4.7+\tau) \mathrm{MPa}$. The concrete creep with eight parameters is used:

$$
\begin{aligned}
C(t, \tau)= & \left(0.0016+62.6833 \tau^{-0.6294}\right)\left[1-e^{-0.3615(t-\tau)}\right] \\
& +\left(2.3562+51.881 \tau^{-0.6036}\right)\left[1-e^{-0.0134(t-\tau)}\right] \\
& \times 10^{-6} \text { per } \mathrm{MPa},
\end{aligned}
$$

where $\tau$ is the concrete loading age and $t-\tau$ is the holding time.

3.4. The Range of the Temperature-Control Parameters. According to the engineering practice of sluice construction and the actual conditions of the project, the feasible range of the cooling water temperature is $12 \sim 18^{\circ} \mathrm{C}$, the feasible cooling duration is $3 \sim 6$ days, the feasible surface exothermic coefficient for the pier in the formwork within 7 days is $5 \sim 60.5 \mathrm{~kJ} /\left(\mathrm{m}^{2} \cdot \mathrm{h} \cdot{ }^{\circ} \mathrm{C}\right)$, and the feasible pouring temperature is $15 \sim 21^{\circ} \mathrm{C}$. Next, the above temperature-control parameters are selected as 4 factors according to the uniform design method [17]. For each factor, 4 levels are selected, as shown in Table 2. The cooling water temperature levels are 12, 14, 16 , and $18^{\circ} \mathrm{C}$, the cooling duration levels are $3,4,5$, and 6 days, the surface exothermic coefficient levels are 5, 23.5, 42, and $60.5 \mathrm{~kJ} /\left(\mathrm{m}^{2} \cdot \mathrm{h} \cdot{ }^{\circ} \mathrm{C}\right)$, and the pouring temperature levels are $15,18,21$, and $24^{\circ} \mathrm{C}$.

Sixteen combinations are generated based on the uniform design table $U_{n}\left(q^{s}\right)$, where $U$ refers to the uniform design, $n$ refers to the test times $(n=16), q$ refers to level numbers of each factor $(q=4)$, and $s$ refers to the number of factors $(s=4)$.

\subsection{Learning Sample Preparation of Neural Network Model.} On the basis of the combinations of the temperature-control parameters, the FEM is first applied to simulate the temperature field and then to simulate the thermal stress field for the bottom slab and pier. In the analysis, the bottom slab concrete pouring is first simulated, and then the pier concrete pouring is simulated. The time interval between the bottom slab and pier concrete pouring is 20 days, and the simulation time of the sluice pier is 30 days. The pier concrete is protected by formwork pasted by the insulation material on the outside for 7 days, and then the formwork is removed. At 1-day internal, the concrete pier surface is covered by heat insulating materials whose surface exothermic coefficient is $13.53 \mathrm{~kJ} /\left(\mathrm{m}^{2} \cdot \mathrm{h} \cdot{ }^{\circ} \mathrm{C}\right)$. The initial calculation time step is 0.25 days, and the latter calculation time step is 0.5 days.

The maximum temperature and tensile stress of pier concrete for sample no. 1 and no. 2 in Table 3 are given in Figure 4

Since the surface insulation effect for sample no. 1 is strong and the newly poured concrete is protected by formwork for 7 days, the crack risk at the early age is low due to small compressive stress; however, sluice pier concrete suffers a prominent cold hammer imposed by the ambient temperature after formwork removal, and the tensile stress on the surface of the concrete is higher than the tensile strength of concrete. In contrast, the surface insulation effect 
TABLE 3: The learning samples for the neural network model based on the uniform design method.

\begin{tabular}{|c|c|c|c|c|c|c|c|c|}
\hline Number & Factor A & Factor B & Factor C & Factor D & $\begin{array}{l}\text { Maximum tensile stress } \\
\text { inside concrete }(\mathrm{MPa})\end{array}$ & $\begin{array}{l}\text { Maximum tensile stress } \\
\text { on the surface }(\mathrm{MPa})\end{array}$ & $\left(R_{\mathrm{in}}\right)_{\min }$ & $\left(R_{\text {sur }}\right)_{\min }$ \\
\hline 1 & 12 & 3 & 5 & 21 & 2.570 & 3.580 & 0.153 & -0.574 \\
\hline 2 & 12 & 4 & 42 & 15 & 1.650 & 0.393 & 0.321 & -0.680 \\
\hline 3 & 12 & 5 & 23.5 & 18 & 1.910 & 0.719 & 0.235 & 0.528 \\
\hline 4 & 12 & 6 & 60.5 & 24 & 2.180 & 0.524 & 0.034 & -1.732 \\
\hline 5 & 14 & 3 & 60.5 & 18 & 1.840 & 0.462 & 0.239 & -1.158 \\
\hline 6 & 14 & 4 & 23.5 & 24 & 2.316 & 0.849 & 0.092 & 0.147 \\
\hline 7 & 14 & 5 & 42 & 21 & 2.030 & 0.465 & 0.150 & -1.279 \\
\hline 8 & 14 & 6 & 5 & 15 & 2.090 & 2.910 & 0.301 & -0.281 \\
\hline 9 & 16 & 3 & 23.5 & 15 & 1.847 & 0.711 & 0.312 & 0.576 \\
\hline 10 & 16 & 4 & 60.5 & 21 & 2.020 & 0.507 & 0.161 & -1.503 \\
\hline 11 & 16 & 5 & 5 & 24 & 2.747 & 3.660 & 0.080 & -0.611 \\
\hline 12 & 16 & 6 & 42 & 18 & 1.857 & 0.451 & 0.238 & -1.037 \\
\hline 13 & 18 & 3 & 42 & 24 & 2.255 & 0.523 & 0.075 & -1.639 \\
\hline 14 & 18 & 4 & 5 & 18 & 2.435 & 3.420 & 0.198 & -0.504 \\
\hline 15 & 18 & 5 & 60.5 & 15 & 1.684 & 0.464 & 0.307 & -0.931 \\
\hline 16 & 18 & 6 & 23.5 & 21 & 2.196 & 0.786 & 0.149 & 0.292 \\
\hline
\end{tabular}

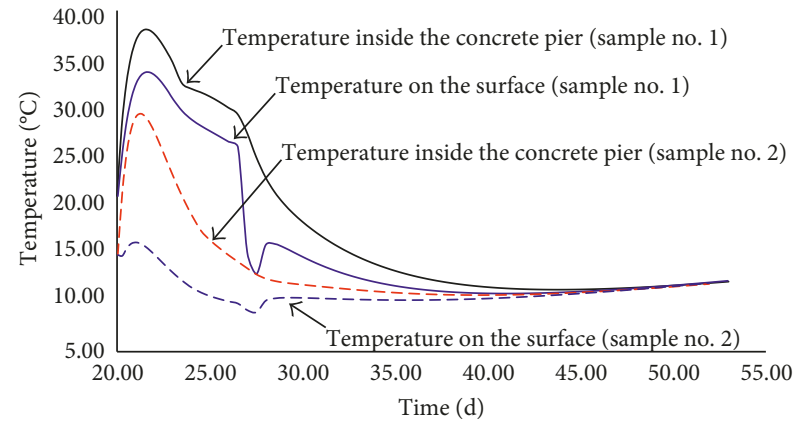

(a)

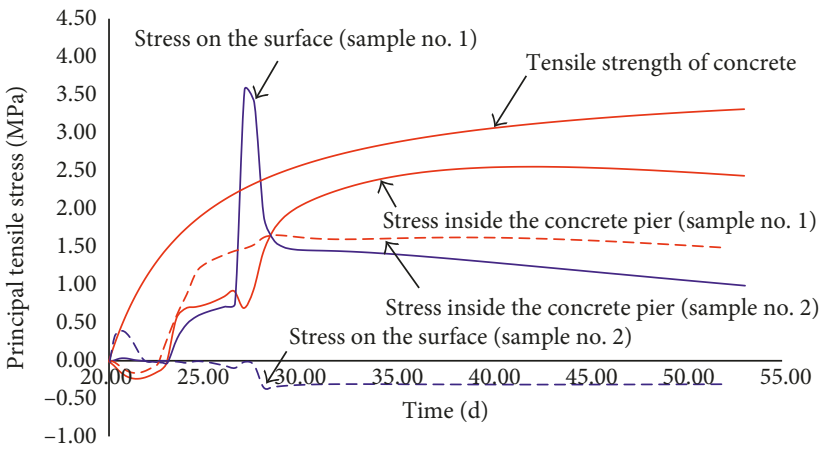

(b)

FIGURE 4: Maximum temperature and maximum tensile stress curves of pier concrete for sample no. 1 and no. 2: (a) temperature curve; (b) tensile stress curve.

for sample no. 2 is weak, and the crack risk at the early age is high due to small concrete tensile strength.

The minimum ratios of the principal tensile stress to the tensile strength at the corresponding age of the inner part and the surface of the pier denoted by $\left(R_{\text {in }}\right)_{\min }$ and $\left(R_{\text {sur }}\right)_{\min }$, respectively, are calculated by (4). Thus, 16 learning samples are generated, as shown in Tables 3 and 4 .

According to Tables 3 and 4, the simulation results show that when the surface insulation effect is strong, large tensile stresses appear on the concrete surface after formwork removal. The tensile stresses are even higher than the tensile strength at the corresponding age. For example, $\left(R_{\text {sur }}\right)_{\min }$ is below zero for sample numbers $1,8,11$, and 14 in Table 3 when the formwork-pasted strong surface insulation material is removed. In contrast, when the insulation effect is weak, the pier concrete may crack at the early age due to the high tensile stress and low tensile strength. Therefore, the optimum temperature control scheme should be investigated based on the simulation results in Table 3 .

3.6. Neural Network Model Training. The back propagation (BP) neural network is one of the most popular techniques in network models [21]. It is a massively parallel distributed processor that has a propensity for storing experimental knowledge and making it available for use. A 3-layer BP network with infinite hidden layer neurons can realize any nonlinear mapping. Specifically, the internal number of hidden layer neurons is first calculated according to $l=\log _{2} n$ and $l=\sqrt{m+n}+a$, where $l, n$, and $m$ are the numbers of hidden layer neurons, input layer neurons, and output layer neurons, respectively, and $a$ is an integer between 0 and 10 . Then, the number of hidden layer neurons $l$ is determined based on the sensitivity analysis for the internal number [1, 12]. Therefore, a 3-layer BP neural network with 10 hidden layer neurons, which is the optimal neural network based on the sensitivity analysis, is adopted. $\left(R_{\text {in }}\right)_{\min }$ and $\left(R_{\text {sur }}\right)_{\min }$ in Table 3 are taken as inputs, and the cooling water temperature, the cooling duration, the surface exothermic coefficient, and the pouring temperature are taken as outputs. To better prevent the "overfitting" issue, the data are normalized before training. After 2000 iterations, the network training is accomplished, and the neural network model is obtained. 
TABLE 4: The ratios of $\left(R_{\text {in }}\right)_{\min }$ and $\left(R_{\text {sur }}\right)_{\min }$ correspond to concrete stress and age.

\begin{tabular}{|c|c|c|c|c|c|c|}
\hline Number & $\left(R_{\text {in }}\right)_{\min }$ & $\left(R_{\mathrm{sur}}\right)_{\min }$ & $\begin{array}{c}\text { Corresponding tensile } \\
\text { stress inside concrete }(\mathrm{MPa})\end{array}$ & $\begin{array}{c}\text { Age of tensile stress inside } \\
\text { concrete (days) }\end{array}$ & $\begin{array}{c}\text { Corresponding tensile } \\
\text { stress on the surface }(\mathrm{MPa})\end{array}$ & $\begin{array}{l}\text { Age of tensile stress } \\
\text { on the surface (days) }\end{array}$ \\
\hline 1 & 0.153 & -0.574 & 2.47 & 15.5 & 3.580 & 7 \\
\hline 2 & 0.321 & -0.680 & 1.62 & 8 & 0.322 & 0.25 \\
\hline 3 & 0.235 & 0.528 & 1.63 & 6 & 0.091 & 0.25 \\
\hline 4 & 0.034 & -1.732 & 2.02 & 5.75 & 0.524 & 0.25 \\
\hline 5 & 0.239 & -1.158 & 1.82 & 8 & 0.414 & 0.25 \\
\hline 6 & 0.092 & 0.147 & 2.22 & 8.5 & 0.164 & 0.25 \\
\hline 7 & 0.15 & -1.279 & 1.81 & 6 & 0.437 & 0.25 \\
\hline 8 & 0.301 & -0.281 & 1.99 & 14 & 2.910 & 7 \\
\hline 9 & 0.312 & 0.576 & 1.72 & 9 & 0.155 & 0.5 \\
\hline 10 & 0.161 & -1.503 & 2.01 & 8 & 0.480 & 0.25 \\
\hline 11 & 0.08 & -0.611 & 2.59 & 13.5 & 3.660 & 7 \\
\hline 12 & 0.238 & -1.037 & 1.82 & 8 & 0.391 & 0.25 \\
\hline 13 & 0.075 & -1.639 & 2.21 & 8 & 0.507 & 0.25 \\
\hline 14 & 0.198 & -0.504 & 2.37 & 6.5 & 3.420 & 7 \\
\hline 15 & 0.307 & -0.931 & 1.66 & 8 & 0.371 & 0.25 \\
\hline 16 & 0.149 & 0.292 & 2.08 & 8.5 & 0.136 & 0.25 \\
\hline
\end{tabular}

3.7. Optimization of Temperature-Control Measure Parameters. According to engineering practices, the safety factor of stress is assumed to be 1.5 inside the concrete pier and 2.0 on the surface, and the allowable tensile stress is $2 / 3\left[\sigma_{1}\right]_{\tau}$ inside the concrete and $1 / 2\left[\sigma_{1}\right]_{\tau}$ on the surface, respectively. Here, $\left[\sigma_{1}\right]_{\tau}$ refers to the tensile strength of the concrete at the moment of $\tau$. Therefore, the optimal ratio values between the principal tensile stress and the tensile strength at the corresponding age for the internal and surface points of the sluice pier concrete are given as $R_{\text {in }}^{\text {opt }}=1 / 3$ and $R_{\text {sur }}^{\text {opt }}=0.5$, respectively. By inputting these two values into the trained neural network, the optimal temperature-control parameters are obtained. The optimal cooling water temperature, cooling duration, surface exothermic coefficient, and pouring temperature are $15.06^{\circ} \mathrm{C}$, 3.67 days, $18.23 \mathrm{~kJ} /\left(\mathrm{m}^{2} \cdot \mathrm{h} \cdot{ }^{\circ} \mathrm{C}\right)$, and $15.02^{\circ} \mathrm{C}$, respectively. The optimal parameters are slightly adjusted and then applied in the temperature control of sluice pier concrete. Engineering practices show no structural crack in the sluice pier concrete.

3.8. Analysis of the Importance of Different TemperatureControl Factors. To discuss the importance of different temperature-control factors, $K_{i}$ and $R$ for different factors are calculated, as shown in Table 5 . Here, $K_{i}$ is the sum of the value of $\left(R_{\text {sur }}\right)_{\min }$ at level number $i(i=1,2,3,4)$ of factor $j$ $(j=\mathrm{A}, \mathrm{B}, \mathrm{C}, \mathrm{D})$, and $R$ is the difference between the maximum value and the minimum value of $K_{i}$ in each column.

Table 5 shows that the importance of factor $C$ (surface exothermic coefficient) and factor $\mathrm{D}$ (pouring temperature) is greater than that of factor A (cooling water temperature) and factor B (cooling duration). According to the aforementioned optimization results and FEM results, the relatively low cooling temperature and long duration are not beneficial for pier concrete. Moreover, the surface insulation measure should be moderate; otherwise, early-age cracking and large tensile stresses after formwork removal may occur. In addition, to avoid large tensile stresses, the pouring
TABle 5: $K_{i}$ and $R$ for different temperature-control factors.

\begin{tabular}{lcccc}
\hline & Factor A & Factor B & Factor C & Factor D \\
\hline$K_{1}$ & -2.458 & -2.795 & -1.970 & -1.316 \\
$K_{2}$ & -2.571 & -2.540 & 1.543 & -2.171 \\
$K_{3}$ & -2.575 & -2.293 & -4.635 & -3.064 \\
$K_{4}$ & -2.781 & -2.758 & -5.324 & -3.835 \\
$R$ & 0.323 & 0.502 & 6.867 & 2.519 \\
\hline
\end{tabular}

concrete temperature should be kept low for pump concrete because its semimature age of adiabatic temperature rise is small.

\section{Conclusions}

(1) Temperature control and crack prevention in sluice pier concrete constitute a complex multiple-factor system optimization problem. The uniform design method and a neural network model were employed to conduct the optimization of multiple temperaturecontrol measures with known thermal and mechanical parameters. The minimum ratios between the principal tensile stress and the tensile strength at the corresponding age for the internal and surface points of the sluice pier concrete were taken as inputs, the cooling water temperature, cooling duration, the surface exothermic coefficient, and the pouring temperature were taken as outputs, and a neural network for the optimizing temperature-control measure parameter was established. The steps of optimizing the temperaturecontrol measures based on the uniform design of the neural network model were presented.

(2) Based on a typical sluice project, the neural network for optimizing the temperature-control measure parameter was successfully implemented. The optimal ratios between the internal and surface tensile stress and the tensile strength of the same age can be input into the trained neural network model to 
obtain reasonable temperature-control measures. The following conclusions are obtained: a relatively low cooling temperature and a long duration are not beneficial to concrete, and the surface insulation measure should be moderate. In addition, to avoid large tensile stresses, the pouring concrete temperature should be kept low for pump concrete.

\section{Data Availability}

The data used to support the findings of this study are available from the corresponding author upon request.

\section{Conflicts of Interest}

The author declares no conflicts of interest regarding the publication of this paper.

\section{Acknowledgments}

This study was supported by the National Natural Science Foundation of China under Grant no. 51779130.

\section{References}

[1] Y. F. Ma, Y. M. Zhu, W. M Cao, and Y. Ning, "Effect of internal cooling pipes and external heat preservation on prevention from concrete cracking during construction of sluice pier," Journal of Hydraulic Engineering, vol. 37, no. 8, pp. 963-968, 2006.

[2] B. F. Zhu, "Pipe cooling of concrete dam from earlier age with smaller temperature difference and longer time," Water Resources and Hydropower Engineering, vol. 40, no. 1, pp. 44-50, 2009.

[3] B. F. Zhu and P. Yang, "Semi-mature age of concrete-a new method for improving the crack resistance of mass concrete," Water Resources and Hydropower Engineering, vol. 39, no. 5, pp. 30-35, 2008.

[4] Z. H. Wang, Y. Liu, G. X. Zhang, and W. Hou, "Schematic study on temperature control and crack prevention during spillway tunnel concreting period," Materials and Structures, vol. 48, no. 11, pp. 3517-3525, 2015.

[5] H. B. Wang and J. L. Zhou, "Simulational analysis of thermal stress and crack prevention for large sluice piers during construction," China Civil Engineering Journal, vol. 45, no. 7, pp. 169-174, 2012.

[6] P. Xu, Y. M. Zhu, and N. H. Ben, "Study on thermal cracking control of inverted T-shaped concrete structures during construction," Journal of Hydraulic Engineering, vol. 40, no. 8, pp. 969-975, 2009.

[7] S. Imanzadeh, A. Hibouche, A. Jarno, and S. Taibi, "Formulating and optimizing the compressive strength of a raw earth concrete by mixture design," Construction and Building Materials, vol. 163, pp. 149-159, 2018.

[8] E. Fraile-Garcia, J. Ferreiro-Cabello, E. Martinez-Camara, and E. Jimenez-Macias, "Optimization based on life cycle analysis for reinforced concrete structure with one-way slabs," Engineering Structures, vol. 109, pp. 126-138, 2016.

[9] K. Chaffar, A. Chauchois, D. Defer, and L. Zalewski, “Thermal characterization of homogeneous walls using inverse method," Energy and Buildings, vol. 78, pp. 248-255, 2014.

[10] Z. Bofang and C. Jianbo, "Finite element analysis of effect of pipe cooling in concrete dams," Journal of Construction
Engineering and Management, vol. 115, no. 4, pp. 487-498, 1989.

[11] B. Zhu, "Effect of cooling by water flowing in nonmetal pipes embedded in mass concrete," Journal of Construction Engineering and Management, vol. 125, no. 1, pp. 61-68, 1999.

[12] B. Zhu, Thermal Stresses and Temperature Control of Mass Concrete, China Water \& Power Press, Beijing, China, 2012.

[13] J. K. Kim, K. H. Kim, and J. K. Yang, "Thermal analysis of hydration heat in concrete structures with pipe-cooling system," Computers and Structures, vol. 79, no. 2, pp. 163-171, 2001.

[14] X. H. Liu, C. Zhang, X. L. Chang, W. Zhou, Y. Cheng, and Y. Duan, "Precise simulation analysis of the thermal field in mass concrete with a pipe water cooling system," Applied Thermal Engineering, vol. 78, pp. 449-459, 2015.

[15] S. Qiang, Z. Q. Xie, and R. Zhong, "A p-version embedded model for simulation of concrete temperature fields with cooling pipes," Water Science and Engineering, vol. 8, no. 3, pp. 248-256, 2015.

[16] Y. Y. Huang, Y. H. Zhou, and J. B. Zhou, "Energy analysis of a pipe cooling thermal conduction calculation model," HydroScience and Engineering, vol. 1, pp. 78-81, 2012.

[17] K. T. Fang and C. X. Ma, Orthogonal and Uniform Experimental Design, Science Press, Beijing, China, 2001.

[18] K. T. Fang and Z. H. Yang, "On uniform design of experiments with restricted mixtures and generation of uniform distribution on some domains," Statistics and Probability Letters, vol. 46, no. 2, pp. 113-120, 2000.

[19] C. F. Xin, Q. Lu, C. F. Ai, A. Rahman, and Y. J. Qiu, "Optimization of hard modified asphalt formula for gussasphalt based on uniform experimental design," Construction and Building Materials, vol. 136, pp. 556-564, 2017.

[20] A. Cascardi, F. Micelli, and M. A. Aiello, "An artificial neural network model for the prediction of the compressive strength of FRP-confined concrete circular columns," Engineering Structures, vol. 140, pp. 199-208, 2017.

[21] K. L. Priddy and P. E. Keller, Artificial Neural Networks: An Introduction, SPIE Press, Bellingham, WA, USA, 2005. 


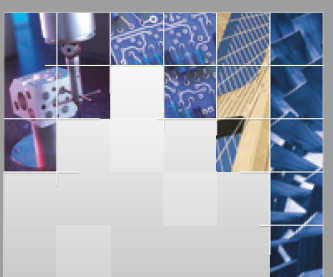

\section{Enfincering}
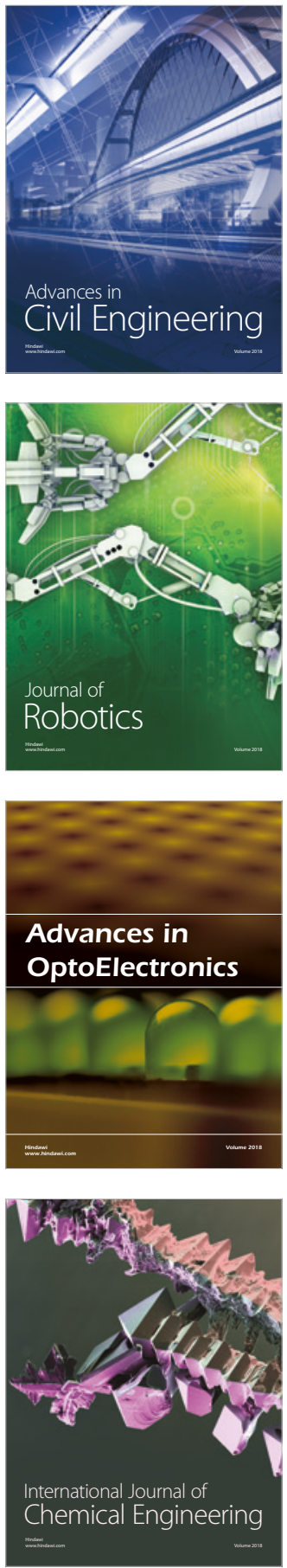

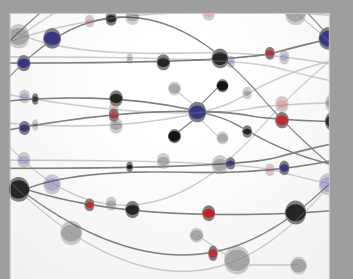

\section{Rotating \\ Machinery}

The Scientific World Journal

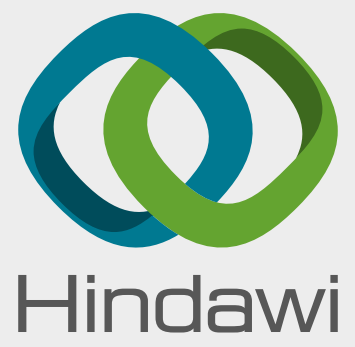

Submit your manuscripts at

www.hindawi.com
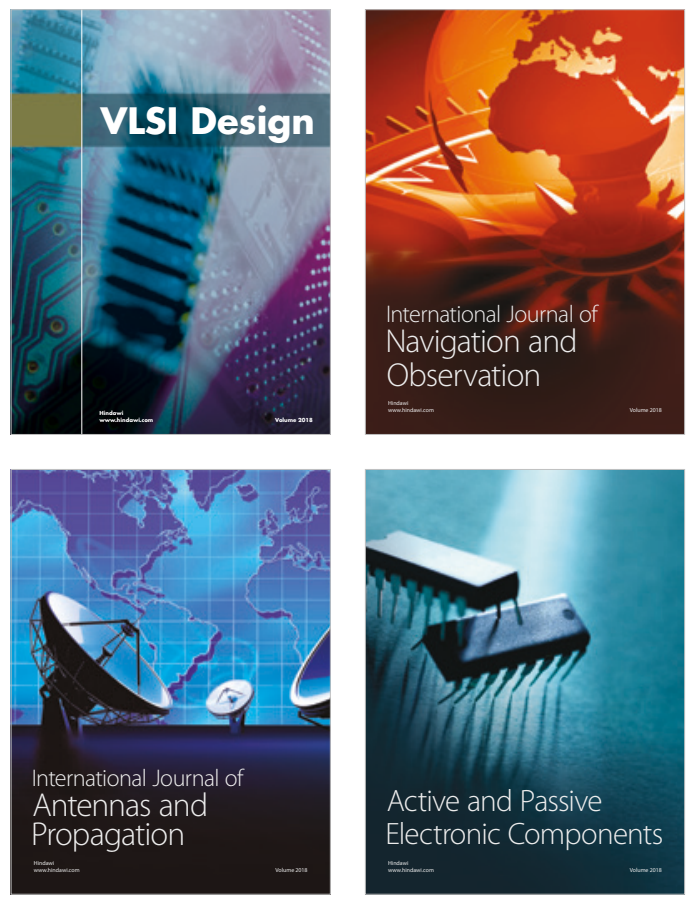
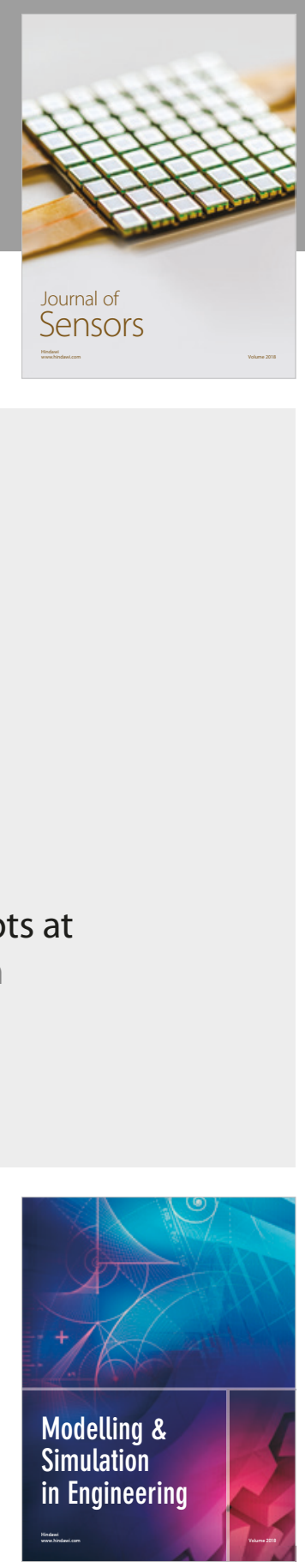

\section{Advances \\ Multimedia}
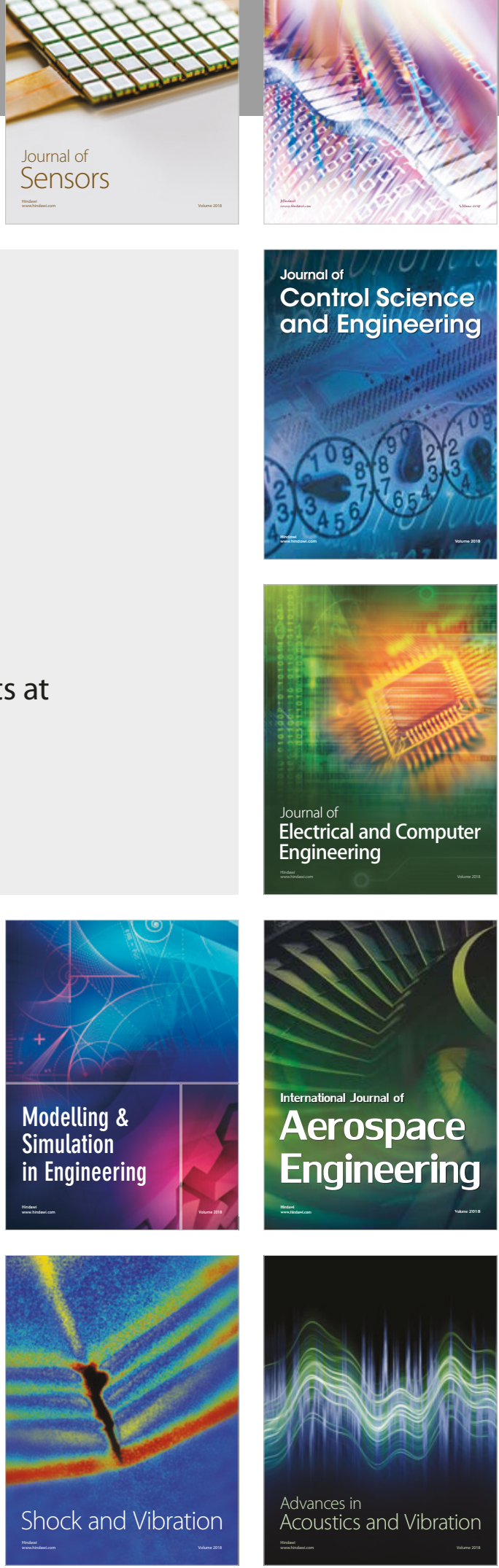